\title{
Design and Development of an Environmental Temperature Controller for Application to a Poultry Environment with an SMS Alert Feature using a Microcontroller: A Risk Reduction Approach
}

\author{
S. O. N. Okonye, U. M Asiwe \\ Department of Electrical and Electronics Engineering, School of Engineering Technology, \\ Delta State Polytechnic, Otefe-Oghara, Delta State, Nigeria
}

\begin{abstract}
How to cite this paper: S. O. N. Okonye | U. M Asiwe "Design and Development of An Environmental Temperature Controller for Application to A Poultry Environment with An SMS Alert Feature Using A Microcontroller: A Risk Reduction Approach" Published in International Journal of Trend in Scientific Research and Development (ijtsrd), ISSN: 24566470, Volume-3 | Issue-3, April 2019, pp.1547-1553, URL: https://www.ijtsrd. com/papers/ijtsrd2 3492.pdf

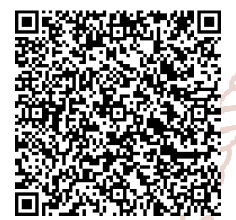

IITSRD23492
\end{abstract}

Copyright (c) 2019 by author(s) and International Journal of Trend in Scientific Research and Development Journal. This is an Open Access article distributed under the terms of the Creative Commons

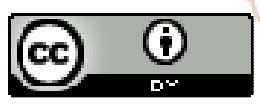
Attribution License (CC BY 4.0) (http://creativecommons.org/licenses/ by $/ 4.0$ )

\section{BACKGROUND OF THE WORK}

In recent times, the livestock sector of the industry has made tremendous adjustment to meeting the increased demands for inexpensive and safe supply of meat and eggs. In the past three years, the livestock sector has been growing at more than 5 percent per annum (Gerber, et al, 2006) and its share in world meat production increased from 15 percent three years ago to 30 percent currently (Gerber, et al, 2006). This growth has been accompanied by structural changes within the sector characterized by the emergence and growth of "land-independent" (industrial) farming establishments and the intensification and concentration of poultry operations (Kolominskas, et al, 2002). Pressure to lower production costs and increase supply has led to more efficient operations made possible through the shift to larger, specialized and move integrated facilities and through improvements in the use of animal genetics, optimized nutrition and new production technologies. The driving forms behind structural changes in poultry production are no different than those that affect other livestock commodities: Market pull, innovation and economics of scale. Innovation and economics of size that characterized the livestock sector has also served to separate animal production from the crop production. Large specialized facilities today focus on producing animals and most of their feeds (Ferket, et al, 2002)

\subsection{LITERATURE SURVEY}

In poultry and in general livestock farming, methods must be developed to reduce risk to a very low value so that profit can accrue to the farmer. Pannell et al. (2000) concluded that 'getting the big decisions right' is the key for farmers to achieve their objectives of staying in farming and increasing their wealth. By 'big decisions' they meant land purchases, machinery investment and resource improvements. In many areas of the world livestock production is closely linked to general economic development (Jahnke, 1983). Livestock diseases dramatically influence the pattern of livestock development in many regions, the effects being 
manifested by premature death, reduced quantity, quality and value of livestock and livestock products, and denial of access to better markets (Morris and Meek, 1979). These diseases thrive in environments where the atmospheric temperature favours their growth and spread. This increases the risk of loosing hard earned investment.

Beal (1996) stated that it is to be expected that risk management strategies adopted by farm managers reflect their personal perceptions of risk.

The metabolic processes poultry in birds is temperature dependent. And if not controlled may lead to high mortality rates. This increases the risk factor involved for farmers. The risk environment of farmers is changing, in part due to increasing market liberalization, technology and industrialization of agriculture (Boehlje and Lins, 1998). These changes has led to new risks, and new risk management instruments being developed. It is the intention of this work to develop a method to help poultry farmers to reduce the risk involved in their operations and hence give them high returns for their investment.

\section{SYSTEM ARCHITECTURE}

The various sections contained in this system are as follows;

$>$ power supply unit

$>$ temperature sensor

$>$ GSM transmitter

$>$ Keypad

$>$ Heat control

$>$ Temperature control

$>$ display

$>$ microcontroller unit

\subsubsection{TRI:}

This is the step down transformer. A transformer voltage of 12 Vac or above is required. The current should be enough to supply the requirement of the circuit.

The transformer (T1) chosen is: 12Vac@300mA.

\subsubsection{D1-D4:}

These are the rectifier circuit. The diodes chosen must have a peak inverse voltage (PIV) that must be able to withstand twice the peak voltage $\left(\mathrm{V}_{\mathrm{p}}\right)$ of the transformers output and a forward current $\left(D_{c}\right)$ of 1.5 times the output current of the transformer.

$$
\mathrm{V}_{\mathrm{p}}=\sqrt{2} \mathrm{Vrms} \quad 1
$$

Where $V_{p}$ is the peak voltage of the transformer output, $V_{\text {rms }}$ is the actual output voltage from the transformer $=12 \mathrm{Vac}$

$$
\begin{array}{ccc}
\mathrm{V}_{\mathrm{p}}=\sqrt{2} \times 12 & =1.414 \times 12=16.97 \mathrm{Vac} \\
\mathrm{D}_{(\text {piv) }}= & 2 \times \mathrm{Vp} & 2
\end{array}
$$

Where $\mathrm{D}_{\text {(piv) }}$ is the PIV of the rectifier diode

$$
\begin{array}{lc}
\text { Therefore, } & D_{\text {(piv) }}=2 \times 16.97=33.94 . \\
\text { And } & D c=1.5 \times 300 \times 10^{-3} \mathrm{~A}=0.45 \mathrm{~A}
\end{array}
$$

The system architecture diagram for the complete system is as shown below:

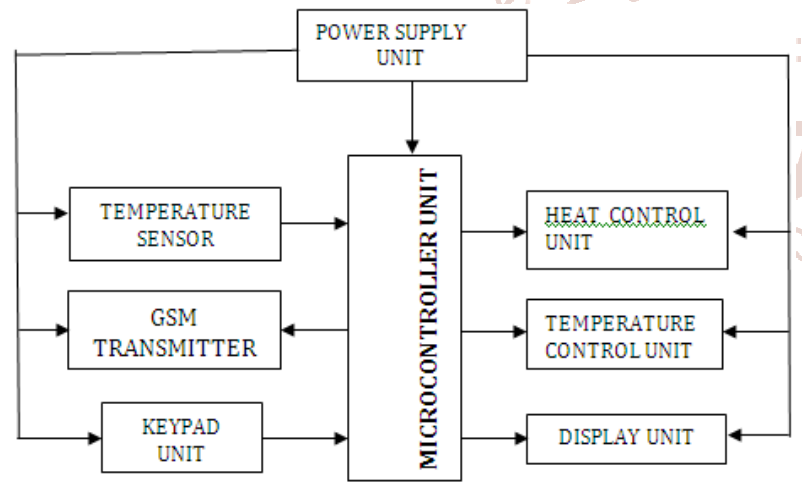

Fig. 1: The System Architecture

\subsection{POWER SUPPLY UNIT}

This is the circuit that supplies power to the full system. The system obtains its power source from a 220 voltas ac power supply source, to deliver a 5 volts output

The circuit diagram is as shown below.

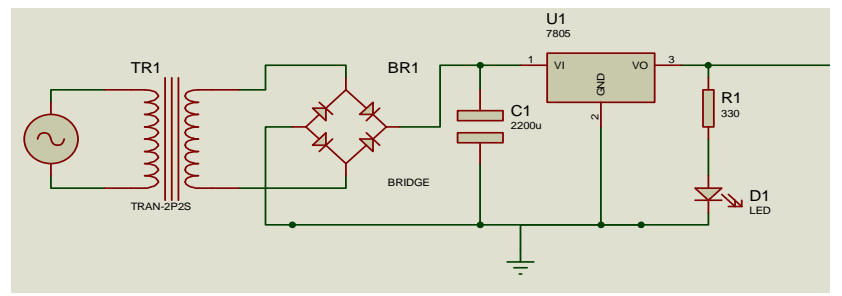

Fig.2: Power Supply Circuit
Therefore the required diode must have a:

$\mathrm{PIV} \geq 33.94 \mathrm{~V}$ and $\mathrm{Dc} \geq 0.45 \mathrm{~A}$

From diode catalogue, the IN4007 has the following characteristics:

$$
\mathrm{PIV}=50 \mathrm{~V} \text { and } \mathrm{D}_{\mathrm{C}}=1 \mathrm{~A}
$$

Consequently, the diode chosen is the IN4007: $\mathrm{D}_{1}-\mathrm{D}_{4}=$ IN4007

\subsection{3 $C_{1}$ :}

This is the filters capacitor. Electrolytic capacitors come with a capacitance and a voltage rating.

\section{A. Voltage Rating}

The voltage of the capacitor $\left(\mathrm{V}_{\mathrm{c}}\right)$ must be able to withstand $150 \%$ of the output voltage from the diode.

$$
V_{C}=150 \% \text { of } V_{D P}
$$

Where $V_{D P}$ is the peak output voltage from the diodes But $V_{D P}$ is given as:

$$
\mathrm{V}_{\mathrm{DP}}=\mathrm{V}_{\mathrm{p}}-\mathrm{V}_{\mathrm{D}}
$$

Where $V_{p}$ is the peak voltage of the transformer $V_{D}$ is the voltage drop of the diodes $(0.7 \times 2)$

$$
\mathrm{V}_{\mathrm{DP}}=16.97-1.4=15.57 \mathrm{~V}
$$

Vc is the voltage rating of the capacitor

$$
\mathrm{Vc}=1.5 \times 15.57=23.6 \mathrm{~V}
$$

\section{B. Capacitance Rating:}

The capacitance of the capacitor must be such that it could reduce the ripple voltage $\left(V_{R}\right)$ to about $30 \%$ of the output peak voltage from the diodes.

$$
V_{R}=30 \% \text { of } V_{D P}
$$

But $\mathrm{V}_{\mathrm{DP}}$ is given as $15.57 \mathrm{~V}$

$$
\therefore \quad V_{R}=\frac{30}{100} \times 15.57=4.67 \mathrm{~V}
$$

From the ripple voltage equation, we could get the capacitance. 


$$
\mathrm{V}_{\mathrm{R}}=\frac{\mathrm{Imax}}{2 \mathrm{x} \mathrm{f} \mathrm{Cl}}
$$

Where $V_{R}$ is the ripple voltage

$I_{\max }$ is the maximum current from the diodes/transformers $(300 \mathrm{~mA})$

$\mathrm{f}$ is the frequency of supply $(50 \mathrm{~Hz})$

$\mathrm{C}$ is the capacitance of the capacitor in Farads. $\mathrm{V}_{\mathrm{R}}=4.67 \mathrm{~V}$ (from eqn 5)

$$
\therefore \quad \mathrm{C}_{1}=\frac{\operatorname{Imax}}{\mathrm{v}_{\mathrm{R}} \times 2 \times \mathrm{f}}
$$

Substituting,

$\mathrm{C}_{1}=\frac{500 \times 10^{-\mathrm{z}}}{4.67 \times 2 \times 50}{ }^{1}=\frac{0.3}{467}=6.42 \times 10^{-4} \mathrm{~F}=642.4 \mu \mathrm{F}$

$\mathrm{C}_{1}=1000 \mu \mathrm{F} @ 35 \mathrm{~V}$ (nearest preferred value)

\subsubsection{U1:}

This is the voltage regulator.

Regulator specifications I:

$>$ Maximum input voltage $=30 \mathrm{~V}$

$>$ Maximum output voltage $=5.5 \mathrm{~V}$

$>$ Operating temperature $=0^{\circ} \mathrm{C}-150^{\circ} \mathrm{C}$

For effective Voltage regulation, the minimum input voltage should be:

$$
\mathrm{V}_{\text {min }}=\mathrm{V}_{\text {out }}+\mathrm{V}_{\text {ref }}
$$

$\mathrm{V}_{\text {min }}$ - Minimum input voltage

$\mathrm{V}_{\text {out }}$ - required output voltage: $5 \mathrm{~V}$

$\mathrm{V}$ ref - Datasheet Stipulated reference voltage; $3 \mathrm{~V}$

$$
\begin{gathered}
\mathrm{V}_{\text {min }}=5+3 \\
\mathrm{~V}_{\text {min }}=8 \mathrm{~V}
\end{gathered}
$$

The output voltage after the capacitor is 15.57 volts. This is enough to supply the minimum input voltage ( 8 volts) Therefore, the voltage regulator could be comfortably used. The regulator chosen is: $\mathrm{U}_{1}=7805$

\subsection{5 $C_{2}$}

is a transient capacitor. The rating is stipulated in the 78XX voltage regulator's data sheet as $0.1 \mathrm{Uf}$. Hence, $\mathrm{C}_{2}=0.1 \mathrm{uF}$ This capacitor helps for smoothening of the output from the voltage regulator. It is also to prevent spikes in the DC output voltage waveform in the event of transient disturbances. It is known as a buffer capacitor whose value is gotten from the data sheet of the regulator.

\subsubsection{Current limiting resistor calculation:}

$$
\begin{gathered}
\mathrm{R}_{1}=\frac{V_{S}-V_{D}}{l_{D}} \\
R_{1}-\frac{5-2}{10 \times 10^{-i}}=300 \Omega \\
\mathrm{R}_{1}=330 \Omega \text { (nearest preferred value) }
\end{gathered}
$$

\subsubsection{Light emitting diode characteristics:}

Forward current of $10 \times 10^{-3} \mathrm{~A}$ to $20 \times 10^{-3} \mathrm{~A}$

Voltage drop of $2 \mathrm{~V}$

\subsection{TEMPERATURE SENSOR UNIT}

The temperature fan is controlled by the ambient temperature. This unit ensures that the ambient temperature is constantly being monitored and the fan will automatically turn on when the temperature is above a certain set reference and will also turn off if the temperature is below the set reference.

The circuit diagram of this unit is divided into two sections

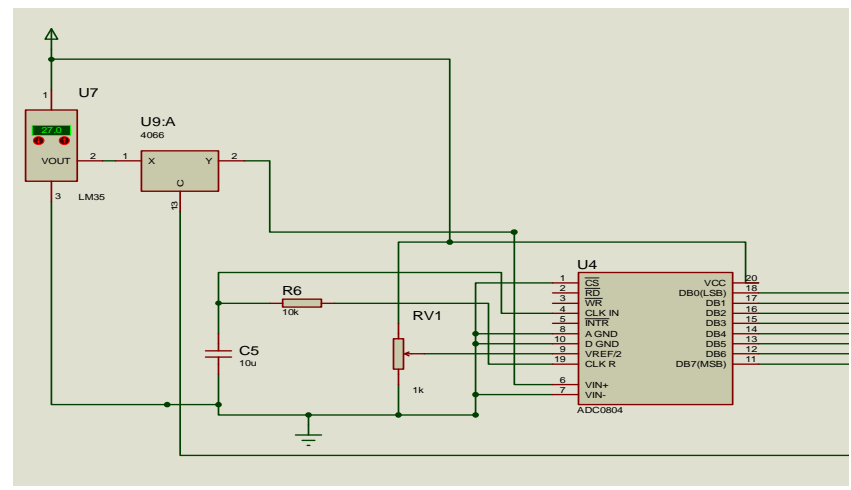

Fig. 3: The Temperature Control Fan Circuit

\subsubsection{U7:}

this is a temperature sensor and it has the following general description and features from the data sheet General description

The LM35 series are precision integrated-circuit temperature sensors, whose output voltage is linearly proportional to the Celsius (Centigrade) temperature. The LM35 thus has an advantage over linear temperature sensors calibrated in ${ }^{\circ}$ Kelvin, as the user is not required to subtract a large constant voltage from its output to obtain convenient Centigrade scaling. The LM35 does not require any external calibration or trimming to provide typical accuracies of $\pm 1 / 4^{\circ} \mathrm{C}$ at room temperature and $\pm 3 / 4^{\circ} \mathrm{C}$ over a full -55 to $+150^{\circ} \mathrm{C}$ temperature range. Low cost is assured by trimming and calibration at the wafer level. The LM35's low output impedance, linear output, and precise inherent calibration make interfacing to readout or control circuitry especially easy. It can be used with single power supplies, or with plus and minus supplies. As it draws only $60 \mu \mathrm{A}$ from its supply, it has very low self-heating, less than $0.1^{\circ} \mathrm{C}$ in still air. The LM35 is rated to operate over a $-55^{\circ}$ to $+150^{\circ} \mathrm{C}$ temperature range, while the $\mathrm{LM} 35 \mathrm{C}$ is rated for a $-40^{\circ}$ to $+110^{\circ} \mathrm{C}$ range $\left(-10^{\circ}\right.$ with improved accuracy). The LM35 series is available packaged in hermetic T0-46 transistor packages, while the LM35C, LM35CA, and LM35D are also available in the plastic T0-92 transistor package. The LM35D is also available in an 8-lead surface mount small outline package and a plastic T0-220 package.

\section{Features}

$>$ Calibrated directly in ${ }^{\circ}$ Celsius (Centigrade)

$>$ Linear $+10.0 \mathrm{mV} /{ }^{\circ} \mathrm{C}$ scale factor $\mathrm{n} 0.5^{\circ} \mathrm{C}$ accuracy guaranteeable (at $+25^{\circ} \mathrm{C}$ )

$>$ Rated for full $-55^{\circ}$ to $+150^{\circ} \mathrm{C}$ range $\mathrm{n}$ Suitable for remote applications

$>$ Low cost due to wafer-level trimming n Operates from 4 to 30 volts

$>$ Less than $60 \mu \mathrm{A}$ current drain

$>$ Low self-heating, $0.08^{\circ} \mathrm{C}$ in still air

$>$ Nonlinearity only $\pm 1 / 4^{\circ} \mathrm{C}$ typical

$>$ Low impedance output, $0.1 \Omega$ for $1 \mathrm{~mA}$ load 
2.2.2 U4: this is the analogue to digital converter integrated circuit.

\begin{tabular}{|c|c|c|}
\hline Pin No & Function & Name \\
\hline 1 & Activates ADC; Active low & Chip select \\
\hline 2 & $\begin{array}{l}\text { Input pin; High to low pulse } \\
\text { brings the data from internal } \\
\text { registers to the output pins } \\
\text { after conversion }\end{array}$ & Read \\
\hline 3 & $\begin{array}{l}\text { Input pin; Low to high pulse } \\
\text { is given to start the } \\
\text { conversion }\end{array}$ & Write \\
\hline 4 & $\begin{array}{l}\text { Clock Input pin; to give } \\
\text { external clock. }\end{array}$ & Clock IN \\
\hline 5 & $\begin{array}{l}\text { Output pin; Goes low when } \\
\text { conversion is complete }\end{array}$ & Interrupt \\
\hline 6 & Analog non-inverting input & $\operatorname{Vin}(+)$ \\
\hline 7 & $\begin{array}{l}\text { Analog inverting Input; } \\
\text { normally ground }\end{array}$ & $\operatorname{Vin}(-)$ \\
\hline 8 & Ground $(0 \mathrm{~V})$ & $\begin{array}{l}\text { Analog } \\
\text { Ground }\end{array}$ \\
\hline 9 & $\begin{array}{l}\text { Input pin; sets the reference } \\
\text { voltage for analog input }\end{array}$ & Vref/2 \\
\hline 10 & Ground $(0 \mathrm{~V})$ & $\begin{array}{l}\text { Digital } \\
\text { Ground }\end{array}$ \\
\hline 11 & & D7 in \\
\hline 12 & & D6 \\
\hline 13 & & D5 \\
\hline 14 & & D4 \\
\hline 15 & $9=$ & D3 \\
\hline 16 & C & D2 \\
\hline 17 & $2=$ & D1 1 rel \\
\hline 18 & 80 & $\mathrm{D} 0$ \\
\hline 19 & $\begin{array}{l}\text { Used with Clock IN pin when } \\
\text { internal clock source is used }\end{array}$ & Clock R \\
\hline
\end{tabular}

Table 1: A/D Converter Pin Functions

\subsubsection{R6 and C5:}

these are the discreet components of the CLK IN and the CLK $\mathrm{R}$ terminals. These terminals are for the use of the internal clock of the ADC

CLK IN is an input pin connected to an external clock source. To use the internal clock generator (also called selfclocking), CLK IN and CLK R pins are connected to a capacitor and a resistor, and the clock frequency is determined by

$$
\mathrm{F}=\frac{1}{1.1 R C}
$$

As always, mathematically, when faced with two unknowns, we assume one and calculate for the other. Meanwhile the data sheet of the ADC 0804 stipulated the clocking frequency to be about 110 us.

Therefore: $\mathrm{F}=110 \times 10^{-6}, \mathrm{R}=10 \times 10^{3}$

$$
\mathrm{C}=\frac{1}{11 \mathrm{NF}}=\frac{1}{1.1 \times 1 \mathrm{n} \times 1 \mathrm{n}^{2} \times 1 \mathrm{n} \times 10^{-2}}=150 \times 10^{-12}=150 \mathrm{pF}
$$

\subsubsection{RV1}

for the Vref/2 terminal of the ADC, It is used for the reference voltage. If this pin is open (not connected), the analog input voltage is in the range of 0 to 5 volts (the same as the Vcc pin). If the analog input range needs to be 0 to 4 volts, Vref/2 is connected to 2 volts

$\mathrm{V}$ as 2 Relation to $\mathrm{Vin}$ Range

\begin{tabular}{lll}
\hline Vre/ $/ 2(\boldsymbol{V})$ & Via $(\mathbf{V})$ & Step Size $(\mathbf{m V})$ \\
\hline Not connected & 0 to 5 & $5 / 256-19.53$ \\
\hline 2.0 & 0 to 4 & $4 / 255=15.62$ \\
\hline 1.5 & 0 to 3 & $3 / 256=11.71$ \\
\hline 1.28 & 0 to 2.56 & $2.55 / 256-10$ \\
\hline 1.0 & 0 to 2 & $2 / 256-7.81$ \\
\hline 0.5 & 0 to 1 & $1 / 256=3.90$ \\
\hline
\end{tabular}

Siep size is the smallest clange can be discerned by an ADC

Table 2: Vref/2 Range of Values

For the case of connecting an LM35 to an ADC804. Since the ADC804 has 8-bit resolution with a maximum of 256 steps and the LM35 produces $10 \mathrm{mV}$ for every degree of temperature change, we can condition Vin of the ADC804 to produce a Vout of $2560 \mathrm{mV}$ full-scale output. Therefore, in order to produce the full scale $V_{o v r}$ of $2.56 \mathrm{~V}$ for the ADC804, We need to set

$$
\frac{V_{K E F}}{2}=1.28
$$

This makes $V_{\text {OUT }}$ of the ADC804 correspond directly to the temperature as monitored by the LM35.

To this effect, we need RV1 to be a variable resistor. Therefore, $\mathrm{RV} 1=10 \mathrm{k} \Omega$

\subsection{GSM TRANSMITTER UNIT}

This is the unit that the system uses to send sms to the user in the event that a change in the ambient temperature is detected. This circuit is built around a GSM MODEM.

The SIM900 GSM modem will be used and it will require the connection to the microcontroller via a TTL to RS converter, MX232. The circuit diagram is as shown below.

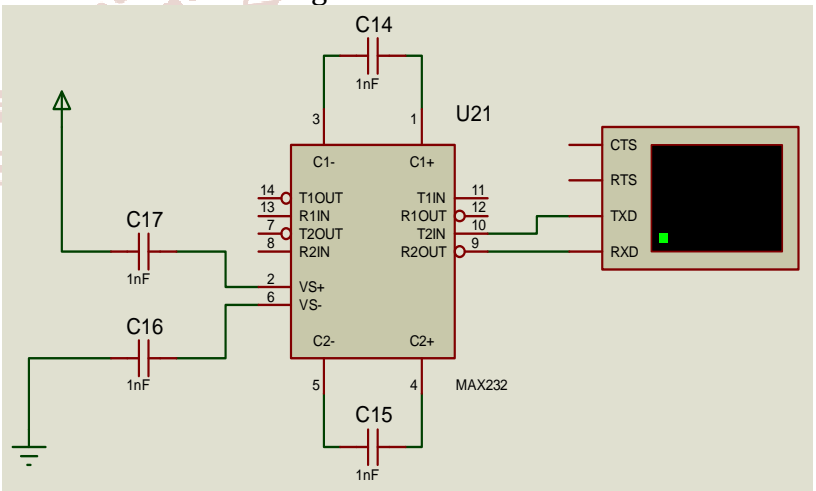

Fig. 4: GSM Transmitter Circuit

The connections for the MAX232 is as lifted off from the data sheet of the integrated circuit.

The GSM modem outputs an RS signal and the max232 converts it to TTL signals which will be readable by the microcontroller.

\subsection{KEYPAD UNIT}

This is the circuit that the system uses to set the reference temperature of the environment. The fan gets triggered when the set temperature is exceeded while the heater turns on when the set temperature drops. The circuit diagram is as shown below 


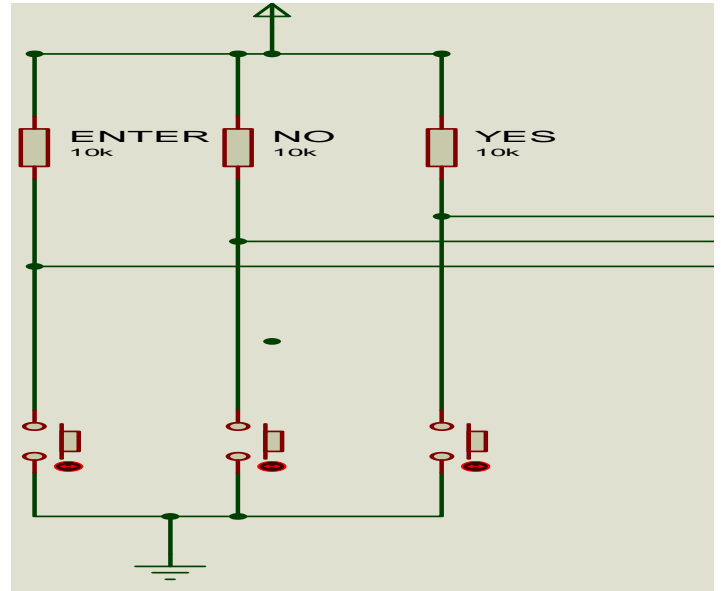

Fig. 5: Key Pad Circuit

R: these are pull up resistors. Pull up resistors are always given a range of values from

$470 \Omega$ to $22 \mathrm{k} \Omega$

For the sake of this design, the value chosen for the pull up resistors values are

$$
\mathrm{R}=10 \mathrm{k} \Omega \text { each }
$$

\subsection{HEAT CONTROL UNIT}

This is the circuit that the system uses to control the heater in the system. The heater responds to the program instructions by the microcontroller and gets turned on when the set reference temperature gets above the ambient temperature. The circuit diagram is as shown below

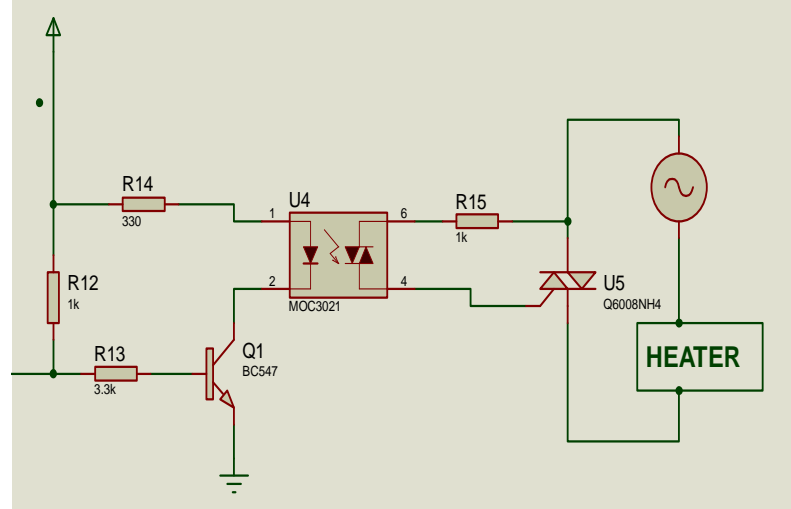

Fig. 6: Heat Control Unit Circuit

The control part of the heater actually turns it off or on. This is basically a switch that is built around a static relay using a triac fired by another triac based opto-isolator. An NPN transistor is used to control the low voltage side of the isolator from signals transmitted from a microcontroller terminal.

$R_{12}=$ a pull up resistor. This is a resistor that is basically used to set a terminal temporarily high. The value is usually from a range of : $470 \Omega$ to $10,000 \Omega$

For this circuit, the value of $1,000 \Omega$ (nearest preferred value).

$R_{14}=$ this is a current limiting resistor for the light emitting diode inside the low voltage side of the Optoisolator. The formula to calculate the value of current limiting resistors is given thus

$$
\mathrm{R}_{14}=\frac{V_{S}-V_{D}}{I_{D}}
$$

From the MOC3021 datasheet, the following characteristics of the low voltage side light emitting diode is given as

Forward current, $I_{\Omega}=10 \mathrm{~mA}$ and Voltage drop $V_{\Omega}=2 \mathrm{~V}$, while the supply voltage for the system is $V_{g}=5 \mathrm{~V}$

$$
\begin{gathered}
R_{14}=\frac{5-2}{10 \times 10^{-3}}=300 \Omega \\
\mathrm{R}_{14}=330 \Omega \text { (nearest preferred value) }
\end{gathered}
$$

$R_{23}=$ this is the biasing resistor for the NPN transistor. For the transistor to work in the saturation mode, we use the equation

$$
R_{B}=10 \times R_{C}
$$

Where $\vec{A}_{B}$ is base resistor

$R_{13}$, and $R_{C}$ is collector resistor $R_{14}(330 \Omega)$

Substituting

$$
R_{B}=10 \times 330 \Omega=R_{13}=3300 \Omega
$$

$R_{15}=$ snubber resistor for the triac on inductive loads. Datasheet stipulates the collective resistance to $1 \mathrm{k} \Omega$ Therefore $R_{\mathrm{IB}}=1,000 \Omega$

\subsection{TEMPERATURE CONTROL FAN}

This is the unit that the system uses to indirectly control the temperature of the environment by powering a temperature controllable fan. This fan will be activated by the microcontroller to turn on each time the temperature of the environment exceeds the set reference temperature and turn off each time it doesn't. The circuit diagram for the unit is as shown below.

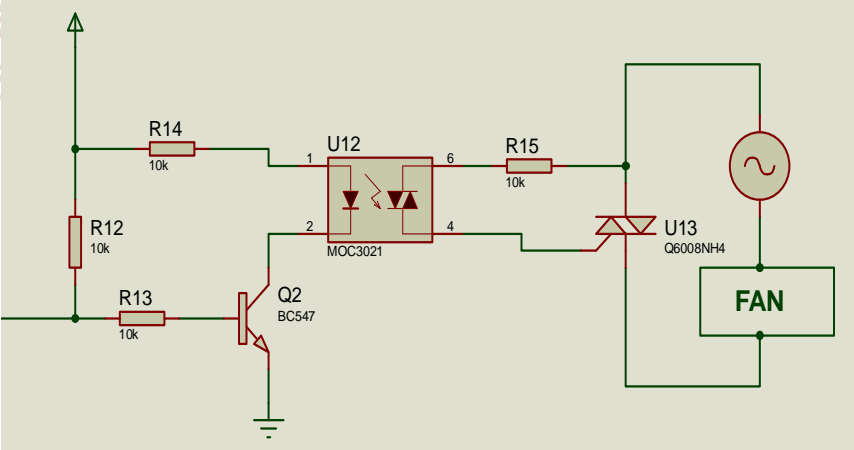

Fig. 7: Temperature Control Fan Circuit

$R_{12}=$ a pull up resistor. This is a resistor that is basically used to set a terminal temporarily high. The value is usually from a range of: $470 \Omega$ to $10,000 \Omega$

For this circuit, the value of $1,000 \Omega$ was used.

$R_{14}=$ this is a current limiting resistor for the light emitting diode inside the low voltage side of the Optoisolator. The formula to calculate the value of current limiting resistors is given thus 


$$
\mathrm{R}_{14}=\frac{V_{S}-V_{D}}{I_{D}}
$$

From the MOC3021 datasheet, the following characteristics of the low voltage side light emitting diode is given as

Forward current, $I_{D}=10 \mathrm{~mA}$ and Voltage drop $V_{D}=2 \mathrm{~V}$

While the supply voltage for the system is $V_{z}=5 \mathrm{~V}$

$$
\begin{gathered}
R_{14}=\frac{\mathrm{s}-2}{10 \times 10^{-3}}=\mathrm{R}_{14}=300 \Omega \\
\mathrm{R}_{14}=330 \Omega \text { (nearest preferred value) }
\end{gathered}
$$

$R_{13}=$ this is the biasing resistor for the NPN transistor. For the transistor to work in the saturation mode, we use the equation

$$
R_{g}=10 \times R_{C}
$$

Where $R_{g}$ is base resistor

$R_{13}$ and $R_{C}$ is collector resistor $R_{14}(330 \Omega)$

Substituting:

$$
R_{5}=10 \times 330 \Omega=R_{14}=3300 \Omega
$$

$R_{15}=$ snubber resistor for the triac on inductive loads Datasheet stipulates the collective resistance to $1 \mathrm{k} \Omega$ Therefore $R_{15}=1,000 \Omega$

\subsection{DISPLAY UNIT}

This is the unit that the system uses to inform the user on the status and progress of the complete circuit. It serves as an interface between the circuit and the user. It displays the current and set temperature of the ambient and the general surroundings. It enables the user to set the desired temperature and guides the user on the progress of the temperature of the system. The circuit diagram is as shown below

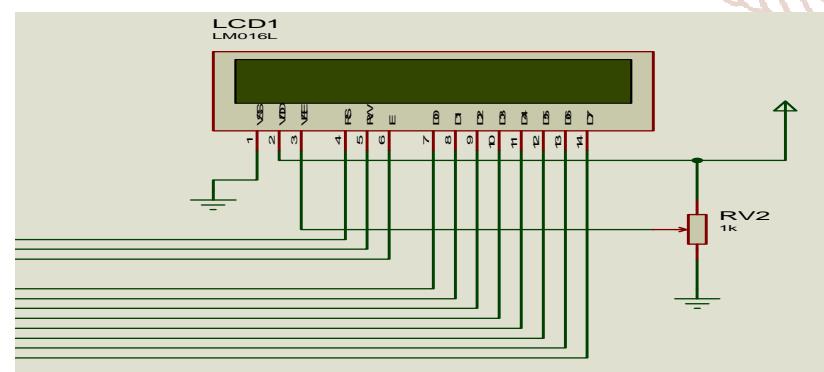

Fig. 8: Display Unit Circuit

The LCD is $16 \times 2$ screen display. This means that it can display 16 alphanumeric characters on 2 lines.

RV2: is a resistor to set the contrast of the display. A $1 \mathrm{k} \Omega$ variable resistor is the usual value used

\subsection{MICROCONTROLLER UNIT}

The microcontroller unit circuit is the heart of the project. This is where the program for the control part of the project is written and burned using assembly language and a universal programmer, respectively. The circuit diagram is as shown below

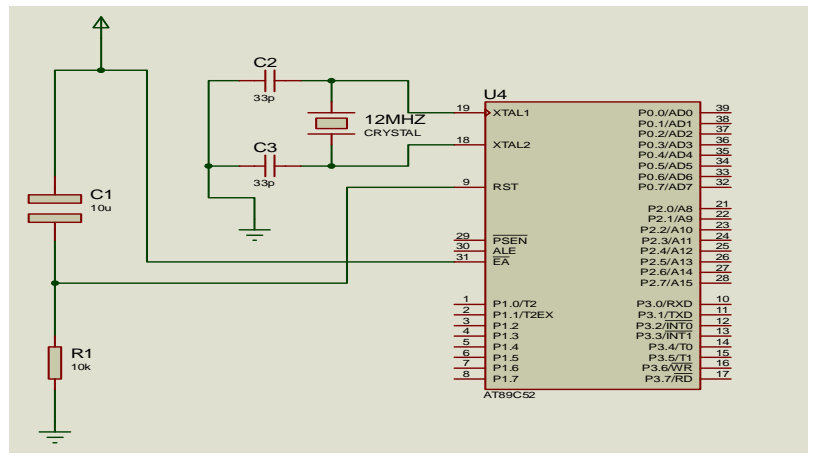

Fig. 9: Microcontroller Unit Circuit

The 8052 microcontroller hardware circuit is usually a very flexible one and all the surrounding components are given a recommended range of values, by the datasheet but the actual values can be chosen by the programmer.

The ranges of values given for the 8052 microcontroller hardware are as follows

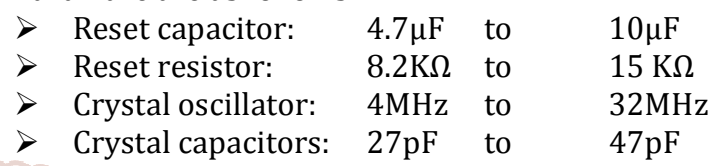

For the programming of the adiabatic temperature environment for a poultry with sms alert, the chosen values are as follows

$>$ Reset capacitor $\left(\mathrm{C}_{1}\right)$ : $\quad 10 \mu \mathrm{F}$

$>$ Reset resistor $\left(\mathrm{R}_{1}\right): \quad 10 \mathrm{~K} \Omega$

$>$ Crystal oscillator $\left(\mathrm{X}_{1}\right)$ : $\quad 12 \mathrm{MHz}$

Crystal capacitors $\left(\mathrm{C}_{2} \& \mathrm{C}_{3}\right)$ : $\quad 33 \mathrm{pF}$

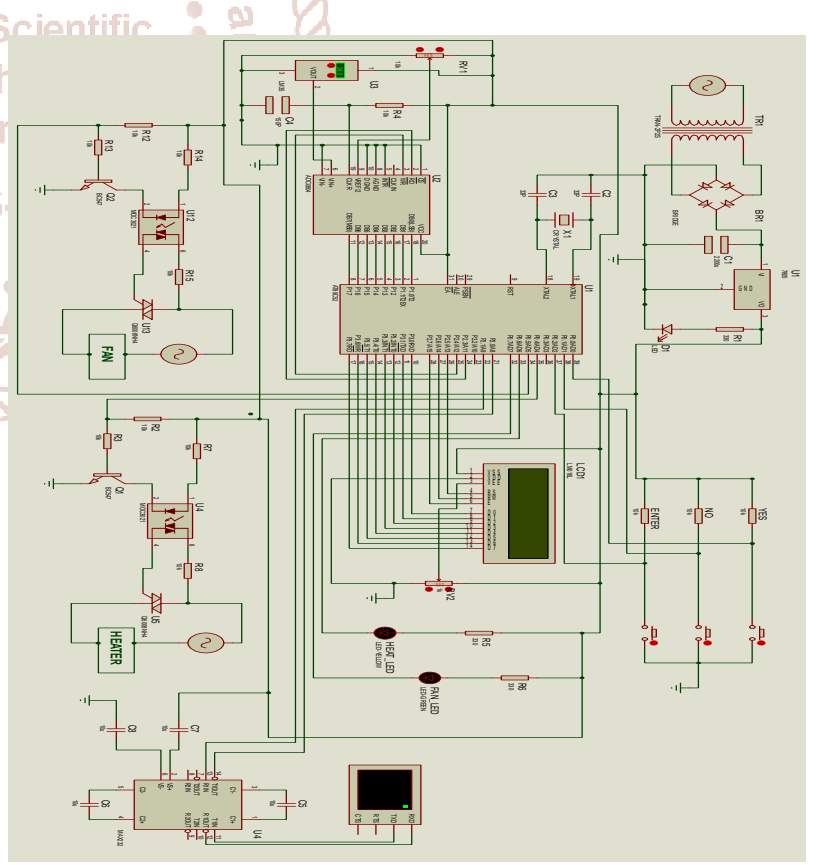

Fig. 10: The System Complete Circuit Diagram

\section{MODE OF OPERATION}

The operation of the environmental temperature controlled system for a poultry environment functions in such a way that the user is prompted to manually set the reference temperature of the poultry environment by the use of the keypads made up of push buttons connected to pull up resistors designated as YES, NO and ENTER. The set reference will be displayed on the screen, then the system will activate the temperature controlled system depending on the set temperature of the environment. If the 
temperature of the environment is higher than the set temperature, the system activates the temperature controlling fan by sending a high signal to transistor Q2, which will activate the low voltage side of the integrated circuit U12, which will in turn activate the fan via triacU13.

On the other hand, when the set temperature is lower that the temperature of the environment, the system will activate the heater. The heater works in virtually the same way as the temperature controlled fan however, using transistor Q1 and integrated circuit $U 4$. The screen displays the set temperature and the current temperature of the system.

Meanwhile each time a temperature change is being performed; the system sends a text message to the user via the MAX232 integrated circuit. This IC is an RS to TTL converter which is interfacing the GSM MODEM (sim900). With this MODEM, the user gets an sms each time the garden changes. The complete system operates on a 5 VDC power supply obtained from a $220 \mathrm{vac}$ power source.

\section{CONCLUSION}

The problem of poultry farming arising from not being able to manage the temperature changes have resulted in many poultry farmers incurring huge financial losses. This paper has taken a close look at this problem and has proposed a dynamic solution using digital hardware and software. This proposed system works efficiently over the present conventional methods of manual observation before action and will help in reducing to a minimum the financial losses and risk farmers are made to incur.

\section{REFERENCES}

[1]. Gerber, et al, (2006) "Reducing security vulnerabilities for critical infrastructure," Journal of Loss Prevention in the Process Industries, vol. 22, no. 6, pp. 1020-1024.

[2]. Kolominskas, et al, (2002) "Guaranteeing Real-Time Services for Industrial Wireless Sensor Networks With IEEE 802.15.4. IEEE Trans. Industr. Electron, vol. 57, pp. 3868-3876.

[3]. Ferket, et al, (2002) "Opportunities and challenges of wireless sensor networks in smart grid," IEEE Trans. on Ind. Elect., vol. 57, no. 10, pp. 3557-3564.

[4]. Pannell DJ, Malcolm B, Kingwell RS (2000) “Are we risking too much? Perspectives on risk in farm modelling", Agricultural Economics 23, 69-78.

[5]. Jahnke, H. E (1983) "Livestock in Economic Development. In: Peel, L. J., Tribbe, D. E. (Eds), Domestication Conservation and Use of Animal Resources", Elsevier, Amsterdam, pp. 307-329

[6]. Boehlje, M. D., Lins, D. A., (1998) "Risks and Risk Management In Perceptions and Management Responses of Arizona Dairy Industrialised Agriculture”. Agric. Fin. Rev. 58, 1-16.

[7]. Morris, R. S., Meek, A. H., (1979) "Measurement and Evaluation of the Economic Effects of Parasitic Disease", Veterinary Parasitol 6, pp. 165-184. 